\title{
Personality as Predictors of Academic Achievement among University Students
}

\author{
Saima Hafiz ${ }^{1 *}$
}

\section{ABSTRACT}

There are various factors which contribute to academic success. Personality is one of those which are very important in determining the academic success. With the advancement of science and technology, we are more inclined towards bad living styles so does influence our personality as well. Academic achievement is defined as one's capability to achieve success by utilizing skills. It is considered as means of excellence to achieve success in one's life. The paper intends to investigate different personality dimensions as predictors of academic achievement. Personality can be defined as a collection of emotional, thought and behavioral patterns that are unique to each person and stable over time. NEO- five factor inventory was administered to collect data among the respondents. A sample of 60 students including male and female was taken for the study. Step wise regression was applied to analyze the data. This study will help in determining the dimensions those results in academic success. The implications of the study are further elucidated.

Keywords: Personality traits, CGPA, University students, Step wise regression.

Academic achievement is conceptualized as the process in which a learner is profiting from instruction to the extent that skill and knowledge has been imparted as a part of leaning (Crow and Crow, 1969). Research on this area has been increasing day by day as it has an influencing role to play in molding child's career. It impacts academic success in terms of future opportunities. Due to the growing demands of parents it has become necessary part of research to find the factors of personality which contribute in achieving success. There are number of factors which are related to academic achievement but personality is an important determinant of academic success. Personality is conceptualized as emulsification of the behavior and mental characteristics that are distinctive of an individual. Personality is also described as a categorized set of attributes that is found in a person that influences and defines the individual's cognition, motivations and behaviors (Colman, 2006). Larsen and Buss (2008) state personality as a set of

\footnotetext{
${ }^{1}$ Research Scholar, Department of Psychology, GNDU, Amritsar

*Responding Author

(c) 2016 I S Hafiz; licensee IJIP. This is an Open Access Research distributed under the terms of the Creative Commons Attribution License (http://creativecommons.org/licenses/by/2.0), which permits unrestricted use, distribution, and reproduction in any Medium, provided the original work is properly cited.
} 
psychological traits and mechanisms within an individual that are organized and relatively enduring and that influence his/her interactions with and adaptations to the environment. The five factor approach to personality includes neuroticism, extraversion, and openness to experiences, agreeableness and conscientiousness. McCrae and Costa (1985) states that openness to experience is an important personality factor which distinguish individuals who are open to experiences. The personality traits such as Conscientiousness and agreeableness have the probability to significantly relate to academic success. This signifies that students with high conscientiousness and agreeableness performed better than those low in conscientiousness and agreeableness (Chowdhury and Amin, 2006). The big five factor model of personality is envisioned the role of personality traits in various domains of life. The various dimension i.e. extraversion, neuroticism, conscientiousness, agreeableness, and openness to experience contribute to great extent in academic achievement as they reflect the mood how one perceive, adapt and react to the changing demands or unsettling conditions. Those who are more expressive are better in coping to the stressful situations. Neuroticism $(\mathrm{N})$ is the tendency to experience negative affect and affective instability (anxiety, angry hostility, depression, impulsivity, and vulnerability). Extraversion (E) is the disposition toward energetic activity and sociability (warmth, gregariousness, assertiveness, excitement seeking, and positive emotion). Openness (O) is the interest in experiencing novel people, ideas, and things, as well as intellectual and esthetic tendencies (fantasy, feelings, values). Agreeableness (A) is a tendency toward warmth and amiability (altruism, trust, compliance, tender-mindedness, straightforwardness, and modesty). Conscientiousness (C) entails qualities such as diligence, goal-orientation, fastidiousness, and dependability (self discipline, competence, order, dutifulness achievement striving, and deliberation) (Afshar et al. 2005) (Chapman et al. 2007). Hence, it was documented by researchers that these five factors get influenced in terms of age, gender, and educational level. It was also reported that there are significant differences between men and women in terms of factors such as neuroticism, conscientiousness, and extraversion (Costa, Terracciano, \& McCrae, 2001; Lameiras, \& Rodriguez, 2004; McCrae, \& Terracciano, 2005).

\section{OBJECTIVE:}

This study aims to study the predictors of academic achievement. The predictor variables chosen for the purpose of the study are neuroticism, extraversion, openness, agreeableness and conscientiousness.

\section{Hypothesis:}

Personality traits will be significant predictors of academic achievement

\section{METHOD:}

\section{Sample:}

A sample of 60 students is taken in the age group 18-22 years with equal number of males and females. The sampling technique employed was incidental. The sample is collected from those subjects who are pursuing their degrees from Guru Nanak Dev University, Amritsar. 


\section{Tools:}

\section{NEO-Five Factor Inventory: Costa and McCrae (1992)}

The scale contains 60 items with 12 items assessing each personality factor. It has a five point response format which is used to assess five basic personality factors viz. neuroticism, extraversion, openness, agreeableness and conscientiousness. The big five personality factors provide a framework for basic personality dimensions; they are openness, conscientiousness, extraversion, agreeableness and neuroticism. Neuroticism $(\mathrm{N})$ is the tendency to experience negative affect and affective instability (anxiety, angry hostility, depression, impulsivity, and vulnerability). Extraversion (E) is characterized as energetic and sociability (warmth, gregariousness, assertiveness, excitement seeking, and positive emotion). Openness (O) is the collection of interest in experiencing novel ideas, and things, as well as intellectual and aesthetic tendencies. Agreeableness (A) is an aptness to have warmth and good nature. Conscientiousness (C) entails qualities such as diligence, goal-orientation, fastidiousness, and dependability (Chapman et al. 2007). The internal consistency ranges from 0.75 to 0.89 .

Academic Achievement: CGPA of the participants.

\section{RESULT AND DISCUSSIONS:}

A step wise regression analysis has been used to predict academic achievement from neuroticism, extraversion, openness, agreeableness, conscientiousness.

Result of step wise regression for academic achievement in females

\section{Table 1}

\begin{tabular}{|l|l|l|l|l|l|l|}
\hline Variable & $\mathbf{R}$ & $\mathbf{R}^{2}$ & $\mathbf{B}$ & $\boldsymbol{\beta}$ & $\mathbf{F}$ & Significance \\
\hline Constant & & & 4.97 & & & \\
Extraversion & .84 & .72 & .10 & .85 & 70.7 & .01 \\
\hline
\end{tabular}

Constant: Academic Achievement

A value of 0.85 indicates a level of prediction. The "R Square" column depicts the $\mathrm{R}^{2}$ value (also called the coefficient of determination), which is the proportion of variance in the dependent variable that can be explained by the independent variables. This portrays that extraversion explain $8.4 \%$ of the variability of our dependent variable i.e. academic achievement. The $\mathrm{F}$ ratios are significant for the predictor variable. These findings indicate that those who are expressive are better to cope with the changing situation so that their academic achievement. Extroversion characteristic of personality reflect the intensity and quality of an individual's relationship to the environment; extroverted people seek connection with the environment and are warm, energetic, and sociable (Klinkozs et al.2006). The results of the study are supported by the findings of Rothstein et. al. (1994) that illustrate a positive association between extraversion and academic achievement. There is another study by Akomolafe, M.J (2013) which signifies a positive relationship between extraversion and academic achievement. 
Step wise regression for academic achievement in males

Table 2

\begin{tabular}{|c|c|c|c|c|c|c|}
\hline Variables & $\mathbf{R}$ & $\mathbf{R}^{2}$ & $\mathbf{F}$ & B & $\beta$ & Significance \\
\hline $\begin{array}{l}\text { Constant } \\
\text { Openness }\end{array}$ & .89 & .79 & 107.8 & $\begin{array}{l}4.16 \\
.19\end{array}$ & .89 & .000 \\
\hline $\begin{array}{l}\text { Constant } \\
\text { Openness } \\
\text { Agreeableness }\end{array}$ & .91 & .84 & 71.3 & $\begin{array}{l}3.69 \\
.31 \\
.08\end{array}$ & $\begin{array}{l}.62 \\
.35\end{array}$ & .000 \\
\hline $\begin{array}{l}\text { Constant } \\
\text { Openness, } \\
\text { Agreeableness, } \\
\text { conscientiousness }\end{array}$ & .93 & .87 & 58.4 & $\begin{array}{l}3.35 \\
.10 \\
.08 \\
.04\end{array}$ & $\begin{array}{l}.49 \\
.34 \\
.22\end{array}$ & .000 \\
\hline
\end{tabular}

The above table represents that openness to experience, agreeableness, and conscientiousness are predictors of academic achievement among males. This depicts that those who are open, agreeable and conscientiousness possess greater academic success. The big five personality provides in-depth analysis and framework for explaining the relationship between personality and various academic behaviors (Poropat, 2009). It was documented by researchers that agreeableness, conscientiousness and openness to experiences are predictors of academic achievement. Agreeableness is the tendency to be pleasant, compassionate, cooperative and accommodating in social situations rather than being antagonistic and suspicious of others. An agreeable person is good, natured, cooperative and functioning. It was pointed by researchers that Agreeableness is positively related to academic performance (Lounsbury, Sundstrom, Loveland, \& Gibson, 2003; Farsides \& Woodfield, 2003; Gray \& Watson, 2002). Another dimension of personality, Openness is the degree of intellectual curiosity, creativity and a reference for novelty and variety. There are various studies which have found the positive association between openness and academic achievement (Lounsbury, Sundstrom, Loveland, \& Gibson, 2003) Conscientiousness is a tendency to show self-discipline, act dutifully and aim for achievement amidst various challenges. It was regarded as the more imported factor which has a vital role in achieving academic success. There are studies which have found a positive association between conscientiousness and academic performance (Cornard, 2006). Noftle and Robins (2007) illustrate in the findings of their study that consciousness is the strongest predictor of academic performance and the other form traits have weak or mixed relationship with GPA.

\section{CONCLUSION:}

The present study enclosed the various personality traits which are responsible for achieving academic success. The result of the present study reveals that extraversion is responsible for achieving success among females. On the other hand, openness, agreeableness and 
conscientiousness are predictors of academic achievement among males. This study can access the counselors, career counselors and professionals to take their personal perspective in terms of personality traits and its relationship to academic achievement. These two terms go side by side because personality determines our adjustment to the environment. How we perceive, interpret and react to the situation can be helpful in adapting to the situation and attaining the realms of life and have implications for psychological health.

\section{IMPLICATIONS:}

The personality is an important aspect which makes us adaptable to the changing situation by perceiving, analyzing and interpreting the situation. The big five personality model is the association of various personality traits which reflect the particular domain of life. This study will assist the counselors, mental health professionals to keep in focus the particular traits which is a source of success among adolescents.

\section{REFERENCES:}

Afshar H, Roohafza H, Hassanzadeh-Keshteli A, Sharbafchi MR, Feizi A, Adibi P, (2015). Association of Personality Traits with Psychological Factors of Depression, Anxiety, and Psychological distress: A Community Based Study. International Journal of Body Mind Culture; 2(2):???.

Akomolafe, M.J. (2013). Personality characteristics as predators of academic performance of secondary school students. Mediterranean Journal of Social Sciences, Vol.4 No. 2. ISSN: 2039-2117(online), ISSN: 2039-9340(Print).

Chapman, B., Duberstein, P., \& Lyness, J. M. (2007a). Personality traits, education, and healthrelated quality of life among older adult primary care patients. Journal of Gerontol.B Psychol Sci Soc Sci, 62(6), 343-352.

Chowdhury, M.S, Amin, M.N (2006) Personality and students ${ }^{\text {ee }}$ academic achievement: Interactive effects of conscientiousness and agreeableness on students ${ }^{\text {ee }}$ performance in principles of economics. Social Behavior and Personality. 34 (4), 381-388.

Colman, A. M. (2006) Oxford Dictionary of Psychology Dictionary, Oxford: Oxford University Press.

Conard, M. A. (2006). Aptitude is not enough: How personality and behavior predict academic performance. Journal of Research in Personality, 40, 339-346

Costa, P. T., Terracciano, A., \& McCrae, R. R. (2001). Gender differences in personality traits across cultures: robust and surprising findings. Journal of Personality and Social Psychology, 81(2), 322-331.

Crow, L, D. \& Crow (1969).Adolescent development and adjustment, McGraw-Hill Book Company, United States.45-49.

Dzulkifli, M.A \& Alias, I.A (2012). Students of low academic achievement, their personality, mental abilities and academic performance. How counselor can help. International Journal of humanities and social science. Vol.2, No. 23. 
Farsides, T., \& Woodfield, R. (2003). Individual differences and undergraduate academic success: The roles of personality, intelligence, and application. Personality and Individual Differences, 34, 1225-1243.

Gray, E. K., \& Watson, D. (2002). General and specific traits of personality and their relation to sleep and academic performance. Journal of Personality, 70, 177-206.

Klinkozs, W., Sekowski, A., \& Brambring, M. (2006). Academic achievement and personality in university students who are visually impaired. Journal of Visual Impairment Blindness, 100(11), 666-675.

Lameiras, F. M., \& Rodriguez, C. Y. (2004). Sex differences on the five personality factors in Spanish students. Psychological Report, 95(1), 101-106.

Larsen, R. J., \& Buss, D. M. (2008). Personality psychology: Domains of knowledge about human nature (3rd edition). New York: McGraw-Hill.

Lounsbury, J. W., Sundstrom, E., Loveland, J. M., \& Gibson, L. W. (2003). Intelligence, “Big Five" personality traits, and work drive as predictors of course grade. Personality and Individual Differences, 35, 1231-1239.

Lounsbury, J. W., Sundstrom, E., Loveland, J. M., \& Gibson, L. W. (2003). Intelligence, “Big Five" personality traits, and work drive as predictors of course grade. Personality and Individual Differences, 35, 1231-1239.

McCrae, R., \& Terracciano, A. (2005). Universal features of personality traits from the observer's perspective: data from 50 cultures. Journal of Personality and Social Psychology, 88(3), 547-561.

Meera Komarraju, Steven J. Karau, Ronald R. Schmeck, Alen Avdic (2011). The Big Five personality traits, learning styles, and academic achievement. Personality and Individual Differences 51 472-477.

Noftle, E. E., \& Robins, R. W. (2007). Personality predictors of academic outcomes: Big Five correlates of GPA and SAT scores. Personality Processes and Individual Differences, 93, 116-130.

Poropat, A. E. (2009). A meta-analysis of the five-factor model of personality and academic performance. Psychological Bulletin, 135, 322-338.

Wagerman, S. A., \& Funder, D. C. (2007). Acquaintance reports of personality and academic achievement: A case for conscientiousness. Journal of Research in Personality, 41, 221229.

How to cite this article: S Hafiz (2016), Personality as Predictors of Academic Achievement among University Students, International Journal of Indian Psychology, Volume 3, Issue 3, No. 6, DIP: 18.01.100/20160303 